\title{
EVALUASI PARAMETER STABILITAS KAPAL-KAPAL PENUMPANG KECIL
}

\author{
Wolter R Hetharia ${ }^{1}$, Fella Gaspersz ${ }^{2}$, Amar Feninlambir \\ 1'hethariawr@yahoo.com, ²ella_ambon@yahoo.com, amarfenza@gmail.com
}

Fakultas Teknik Universitas Pattimura

\begin{abstract}
ABSTRAK
Parameter stabilitas kapal-kapal penumpang kecil dengan kecepatan tinggi (speedboat) dievaluasi. Hal ini terkait dengan sering terjadinya kecelakaan di laut terhadap kapal-kapal type ini. Demikian juga untuk operasional kapal-kapal tersebut belum tersedianya informasi tentang parameter stabilitas kapal. Riset diawali dengan survei dan pengambilan data kapal di sekitar Pulau Ambon. Data kapal dikembangkan dan dihitung untuk memperoleh parameter stabilitas kapal (pada sudut kemiringan yang besar). Hasil perhitungan dievaluasi dan disimpulkan bahwa untuk kondisi riil kapal masih aman untuk beroperasi. Akan tetapi untuk kasus-kasus tertentu di laut maka kapal dalam kondisi kritis. Hasil penelitian menyarankan perlu adanya regulasi khusus serta kajian lanjut kapal-kapal kecil terhadap kondisi-kondisi kritis dalam operasional kapal.
\end{abstract}

Kata Kunci: kapal kecil, parameter stabilitas

\section{PENDAHULUAN}

Salah satu aktifitas penting di kawasan Propinsi Maluku dan beberapa propinsi kepulauan lainnya di Indonesia ialah transportasi penumpang antar pulau. Kegiatan transportasi penumpang ini dilakukan dengan kapal-kapal penumpang kecil yang menjangkau jarak pelayaran jarak dekat sampai yang jauh. Transportasi penumpang dengan kapal-kapal cepat berukuran kecil (speed boat) ini banyak dioperasikan karena pergerakan penumpang dan material penting lainnya dibutuhkan secara cepat.

Berbagai peristiwa kecelakaan speed boat di beberapa kawasan perairan di Indonesia ialah berupa kapal terbalik dan tenggelam yang disebabkan oleh kondisi cuaca laut yang buruk serta kesalahan operator kapal. Kecelakaan kapal ini terjadi setiap tahun dan yang berdampak pada kehilangan jiwa dan harta benda di laut. Terdapat alasan lainnya yang berasal dari aspek desain dimana kapal-kapal tersebut dibuat tanpa melalui kajian desain dan justifikasi kelayakan operasional kapal. Kajian awal terhadap speedboat ini bertujuan untuk memperoleh hasil evaluasi parameter stabilitas yang akan digunakan untuk tahapan riset selanjutnya.

\section{KAJIAN TEORI DAN METODE}

\section{Kajian Teori}

\section{Transportasi penumpang \& keselamatan} pelayaran

Transportasi penumpang dengan kapal-kapal kecil kecepatan tinggi di beberapa kawasan perairan di Indonesia adalah merupakan suatu kebutuhan utama. Hal ini penting dimana kawasan ini terdiri dari banyaknya gugusan pulau besar dan kecil sebaran penduduk di pulau-pulau tersebut. Kebutuhan transportasi penumpang dengan kapalkapal cepat berukuran kecil (speed boat) tersedia di berbagai jalur transportasi antar pulau. Hampir di setiap desa pesisir di wilayah kepulauan mempunyai sarana transportasi penumpang dengan kapal tipe ini (Gambar 1).

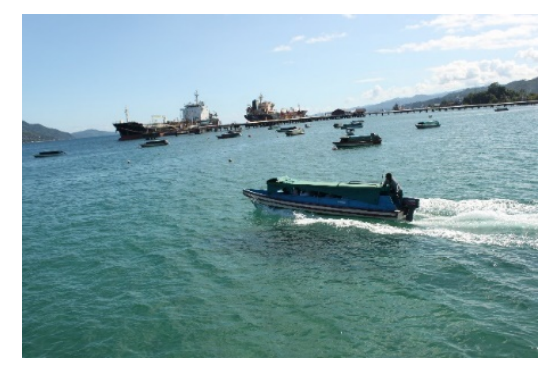

Gambar 1. Speed Boat

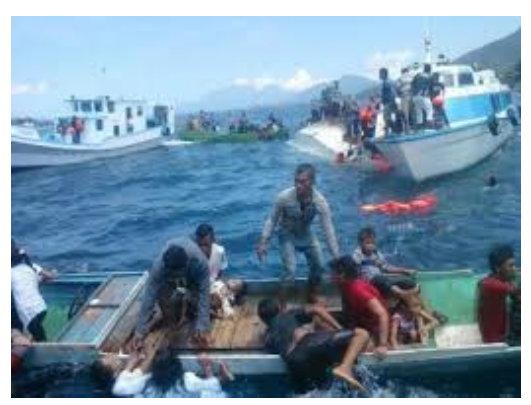

Gambar 2. Operasi penyelamatan penumpang di laut

Riset ini berkonsentrasi pada kapal penumpang dengan kecil kecepatan tinggi dimana sering terjadi kecelakaan kapal yang berdampak pada kehilangan jiwa dan harta benda di laut (Gambar 2). Berbagai kecelakaan yang terjadi diakibatkan oleh faktor cuaca laut yang buruk, disebabkan oleh pemuatan yang berlebihan serta skill operator kapal. Selain itu terdapat beberapa 
kondisi seperti tidak tersedianya peralatan penyelamat, komunikasi dan navigasi yang menghambat penyelamatan jiwa di laut. Kesiapan operator kapal, kelayakan kapal serta ketidak seriusan pihak otoritas pelabuhan dapat menyebabkan musibah kapal sewaktu beroperasi (Hetharia, et.al, 2014). Kejadian tenggelam dan terbaliknya kapal-kapal penumpang kecil di Perairan Maluku maupun beberapa perairan lainnya di Indonesia sering terjadi hampir setiap tahunnya (Data Basarnas, 2016). Di lain pihak, upaya untuk mengatasi masalah ini masih minim sementara operator kapal tetap mengoperasikan kapal dalam kondisi laut buruk atau mengalami kecelakaan laut lainnya.

\section{Konsep dasar pengapungan kapal}

Suatu kapal yang terapung sesuai hukum Archimedes dimana secara singkat dalam teknik perkapalan dinyatakan sebagai: jumlah berat air dari bagian kapal yang tercelup (displasemen) adalah sama dengan berat total kapal tersebut (Parsons, 2003; Watson 2002; Lewis, 1988; Rawson, 1984) dan dinyatakan sebagai :

$$
\begin{array}{ll}
\Delta & =\mathrm{W}_{\text {total }}=W_{L S}+D W T_{T} \\
W_{L S} & =W_{S}+W_{M}+W_{O} \\
D W T_{T} & =D W T_{C}+W_{F O}+W_{C}+W_{P R}
\end{array}
$$

dimana:

$$
\begin{array}{ll}
\Delta & =\text { displasemen berat } \\
\mathrm{W}_{\text {total }} & =\text { berat total kapal } \\
W_{L S} & =\text { berat kapal kosong } \\
D W T_{T} & =\text { bobot mati kapal } \\
W_{S} & =\text { berat struktur kapal } \\
W_{M} & =\text { berat mesin propulsi } \\
W_{O} & =\text { berat perlengkapan } \\
D W T_{C} & =\text { berat penumpang dan bagasi } \\
W_{F O} & =\text { berat bahan bakar dan air } \\
W_{C} & =\text { berat ABK dan bagasi } \\
W_{P R} & =\text { berat provisi }
\end{array}
$$

Sedangkan displasemen berat $\Delta$ dihitung sebagai

dimana:

$$
\Delta=\mathrm{C}_{\mathrm{B}} \times \mathrm{L} \times \mathrm{B} \times \mathrm{T} \times \rho
$$

$$
\begin{aligned}
\mathrm{L} & =\text { panjang kapal; } \\
\mathrm{B} & =\text { lebar kapal; } \\
\mathrm{T} & =\text { tinggi sarat kapal; } \\
\mathrm{H} & =\text { Tinggi Kapal (gedalak) } \\
\rho & =\text { berat jenis air } \\
& =1,025 \text { ton } / \mathrm{m}^{3}, \text { air laut }
\end{aligned}
$$

\section{Stabilitas kapal}

Stabilitas sangat berpengaruh terhadap terbaliknya suatu kapal. Ketika stabilitas suatu kapal tidak layak maka kapal akan terbalik dan selanjutnya kapal tenggelam. Penjelasan stabilitas kapal secara sederhana terlihat pada Gambar 3 berikut ini (Van Dokkum, 2003).
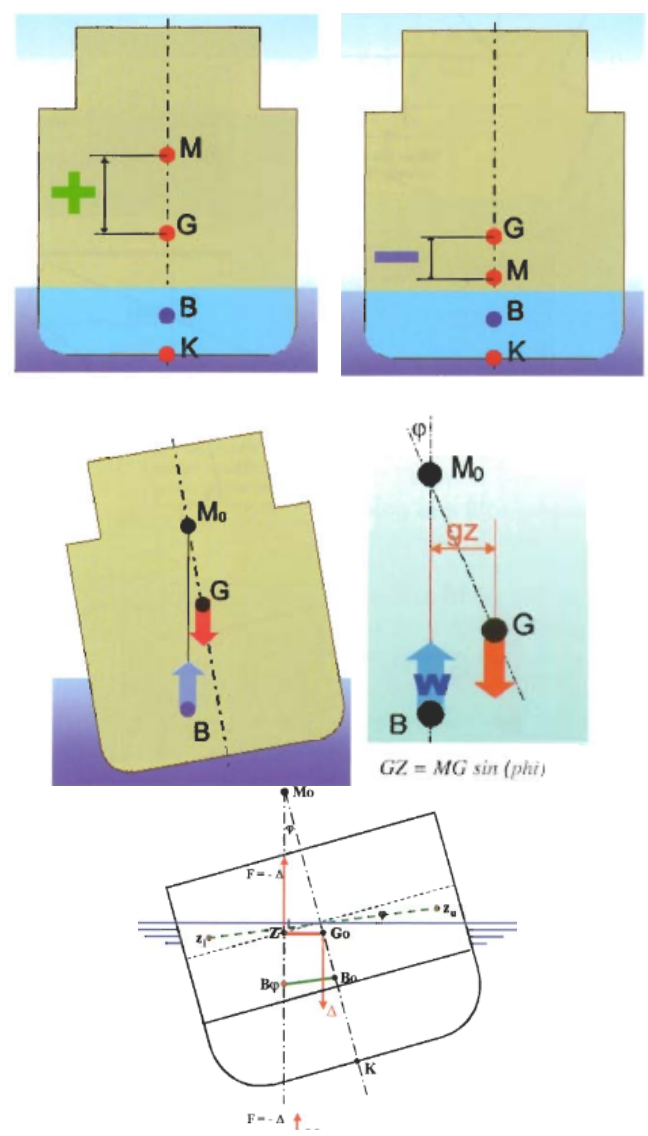

Gambar 3. Komponen Stabilitas Kapal

Komponen stabilitas kapal yang terdiri dari:

Jarak vertikal titik tekan kapal $=\mathrm{KB}$ Jarak Titik berat vertikal kapal $=$ KG.

Radius metasenter melintang kapal $=\mathrm{BM}$

Tinggi metasenter kapal $=\mathrm{GM}$

Lengan stabilitas kapal $=\mathrm{GZ}$

Kriteria stabilitas suatu kapal ditentukan melalui komponen stabilitas "GM" dimana:

$$
\mathrm{GM}=\mathrm{KB}+\mathrm{BM}-\mathrm{KG}
$$

Stabilitas suatu kapal akan layak jika "GM bernilai +" atau "GM $>0$ " dan akan tidak layak jika "GM bernilai -" atau "GM $<0$ ". Ketika terjadi sedikit kemiringan pada kapal dengan sudut kemiringan $\varphi$ maka titik tekan berpindah ke samping sehingga membentuk momen kopel dengan lengan stabilitas:

$$
\mathrm{GZ}=\mathrm{GM} \cdot \sin \varphi
$$

Kondisi ini membuat adanya momen balik dari kapal untuk menegakan kapal ke posisi awal dengan momen balik sebesar 


$$
\mathrm{M}_{\text {balik }}=\Delta \mathrm{xGZ}
$$

Konsep dasar untuk kapal tidak terbalik adalah "nilai GM yang besar". Hal ini dapat dicapai dengan memperbesar lebar kapal untuk menaikan nilai BM atau menempatkan muatan agak ke dasar kapal untuk menurunkan nilai KG. Untuk memperbesar lebar kapal agak menyulitkan dimana kapal-kapal kecil kecepatan tinggi ini akan mengalami hambatan yang besar sehingga kecepatan kapal menurun. Pada prinsipnya dalam mendesain suatu kapal haruslah ada keseimbangan antara komponen stabilitas tersebut.

\section{Metodologi}

Kegiatan riset diawali dengan survei kapal-kapal kecil pada beberapa lokasi di Pulau Ambon. Pengambilan data dimensi dan rencana umum kapal dilakukan di Pantai Kota Jawa Teluk Ambon.

Komputasi parameter hidrostatik dan stabilitas dikembangkan dengan menggunakan Software Maxsurf di Laboratorium Desain Kapal Fakultas Teknik Universitas Pattimura. Evaluasi parameter stabilitas kapal yang merupakan tujuan dari riset ini dilakukan dan ditampilkan pada paper ini.

\section{HASIL DAN PEMBAHASAN}

\section{Data Kapal}

Ukuran pokok kapal terlihat pada Tabel 1 dan rencana garis terlihat pada Gambar 4.

Tabel 1. Ukuran Pokok Kapal

\begin{tabular}{|c|l|l|l|c|}
\hline No & Ukuran Pokok & Simbol & Nilai & Satuan \\
\hline 1 & Panjang Seluruh & $\mathrm{L}_{\mathrm{OA}}$ & 6,61 & $\mathrm{~m}$ \\
\hline 2 & Panjang Garis Air & $\mathrm{L}_{\mathrm{WL}}$ & 6,35 & $\mathrm{~m}$ \\
\hline 3 & Lebar Kapal & $\mathrm{B}$ & 1,40 & $\mathrm{~m}$ \\
\hline 4 & Tinggi Kapal & $\mathrm{H}$ & 0,65 & $\mathrm{~m}$ \\
\hline 5 & Tinggi Sarat & $\mathrm{T}$ & 0,42 & $\mathrm{~m}$ \\
\hline
\end{tabular}

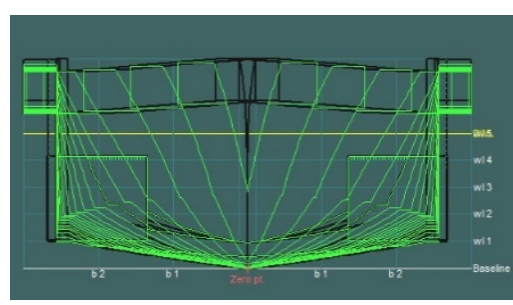

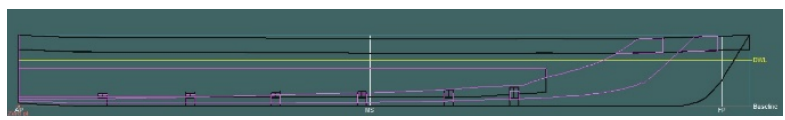

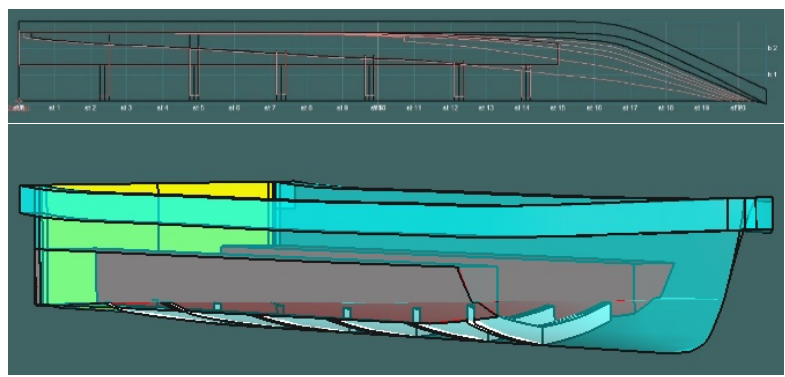

Gambar 4. Rencana Garis

\section{Hidrostatik}

Komponen hidrostatis kapal ditampilkan pada gambar berikut ini.

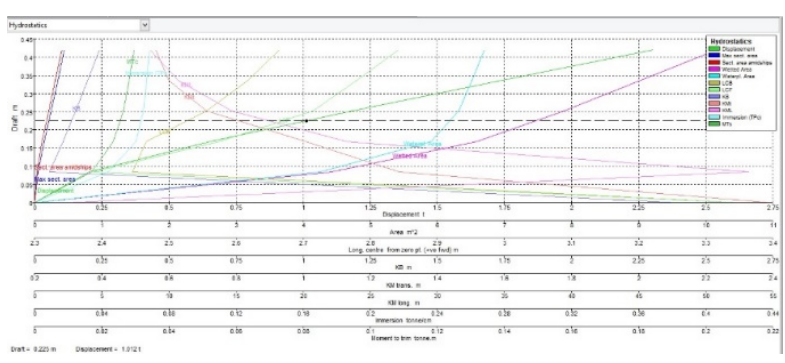

Gambar 5. Komponen Hidrostatis

\section{Pembebanan}

Komponen berat kapal terdiri dari:

Lambung $=963 \mathrm{~kg} \quad$ Motor tempel $=90 \mathrm{~kg}$ Jangkar $\&$ tali $=40 \mathrm{kgBahan}$ bakar $=85 \mathrm{~kg}$

Penumpang 14 dan operator 1 orang $=1125$ $\mathrm{kg}$

Komponen berat tersebut disusun dalam bentuk loadcase untuk eksekusi statilitas kapal seperti terlihat pada Table 2 berikut ini:

Tabel 2. Loadcase Speedboat

\begin{tabular}{|l|c|c|c|c|c|}
\hline \multicolumn{1}{|c|}{ Item } & Quant. & $\begin{array}{c}\text { Unit } \\
\text { mass }\end{array}$ & $\begin{array}{c}\text { L.Arm } \\
(\mathrm{m})\end{array}$ & $\begin{array}{c}\text { T.Arm } \\
(\mathrm{m})\end{array}$ & $\begin{array}{c}\text { V.Arm } \\
(\mathrm{m})\end{array}$ \\
\hline Berat Total & 1 & 2,303 & 2,505 & 0,000 & 0,498 \\
\hline Total Loadcase & & 2,303 & 2,505 & 0,000 & 0,498 \\
\hline
\end{tabular}

\section{Stabilitas Kapal}

Komponen stabilitas kapal terlihat pada Gambar 6 berikut ini. 


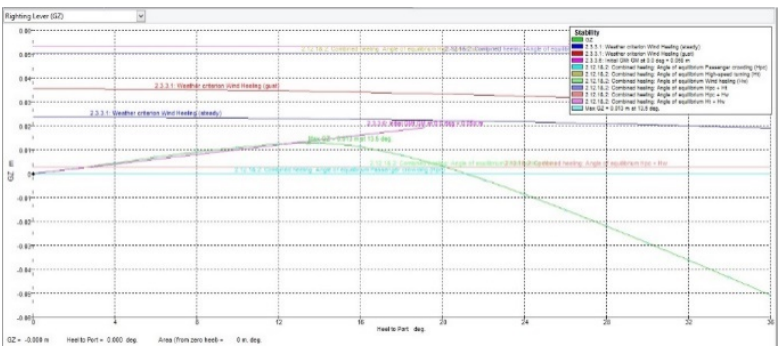

Gambar 6. Komponen Stabilitas Kapal

Komponen stabilitas yang diperoleh adalah:
$\checkmark$ Tinggi titik tekan
$\mathrm{KB}=0,244 \mathrm{~m}$
$\checkmark$ Radius metasenter
$\mathrm{BM}=0,312 \mathrm{~m}$
$\checkmark$ Tinggi titik berat
$\mathrm{KG}=0,498 \mathrm{~m}$
$\checkmark$ Tinggi metasentar
$\mathrm{GMt}=0,058 \mathrm{~m}$
$\checkmark \quad$ Lengan stabilitas max
$\mathrm{GZ}_{\max }=0,013 \mathrm{~m}$ (pada 13,5 derajat)
$\checkmark \quad$ Sudut heel pada GZ $=0 \quad \theta=23$ derajat

\section{Evaluasi Parameter Stabilitas}

Dari hasil komponen stabilitas yang diperoleh terlihat bahwa:

1. Tinggi metasenter GMt $=0,058 \mathrm{~m}$ adalah cukup kecil, namun hal ini terkait dengan kondisi riil kapal.

2. Sudut heel untuk nilai $\mathrm{GZ}=0$ terjadi pada sudut kemiringan $\theta=23$ derajat dinilai aman untuk kapal-kapal ukuran kecil.

3. Lengan stabilitas GZ maximum sebesar 0,013 $m$ terjadi pada sudut kemiringan 13,5 derajat dinilai aman untuk kapal-kapal kecil.

Beberapa faktor penting yang perlu dipertimbangkan terhadap aspek stabilitas adalah:

1. Lebar kapal cukup pendek jika berada pada posisi tegak lurus dengan arah gelombang (beam sea). Hal ini dapat menyebabkan kemiringan kapal yang melebihi sudut heel maximum (23 derajat) yang dapat membahayakan kapal.

2. Ketika penumpang dalam posisi berdiri (untuk suatu kasus dalam pelayaran) maka nilai GZ akan menjadi minus ("“-") sehingga stabilitas kapal menjadi kritis.

\section{KESIMPULAN DAN SARAN Kesimpulan}

Hasil riset ini menghasilkan beberapa kesimpulan berikut ini:

1. Bahwa data hasil evaluasi parameter stabilitas kapal kecil (speedboat) dipresentasikan sesuai kondisi riil dari kapal tersebut.

2. Dari hasil kajian parameter stabilitas terlihat bahwa kapal-kapal tersebut masih dianggap aman untuk beroperasi,

3. Namun ketika kasus-kasus tertentu terjadi di laut seperti posisi kapal pada beam sea atau posisi penumpang dalam keadaan berdiri dapat membahayakan kondisi kapal.

4. Perlu adanya regulasi khusus terhadap aspek keselamatan kapal tersebut

\section{Saran}

1. Perlu adanya kajian lanjutan terhadap kasuskasus krisis seperti kapal kemasukan air ataupun kapal terbalik yang dapat membahayakan keselamatan penumpang dan kapal.

\section{DAFTAR PUSTAKA}

Lewis, E. V., 1988, Pricicles of Naval Architecture, Vol. I, Stability and Strength, SNAME, Jersey City, New Jersey.

Parsons, M. G., 2003, "Parametric Design". Ship Design and Construction - Chapter 11, Vol. 2., SNAME Publication, Jersey City, NJ, USA

Rawson, K. J. and Tupper, E. C., 1984, Basic Ship Theory, Vol. 1, $3^{\text {rd }}$ Edition, Longman, New York.

Taggart, R., 1983, Ship Design and Construction, SNAME Publication, New Jersey.

Watson, D. G. M. (1998). Practical Ship Design. Elsevier Ocean Engineering Book Series, Volume I, ELSEVIER: 48-49, 65-398,

Wolter R Hetharia, Eliza R de Fretes, Fella Gaspersz' Abdul J. Tianotak, 2014, Kajian Tentang Beberapa Aktifitas Masyarakat Maluku di Sektor Kelautan Kajian Tentang Beberapa Aktifitas Masyarakat Maluku di Sektor Kelautan, Prosiding Kongres Budaya Maluku, Ambon

Van Dokkum, K, 2003, Ship Knowledge - A Moderen Encyclopedia, DOKMAR, Enkhuizen, The Netherland. 